DOI: 10.17516/1997-1397-2021-14-1-98-104

УДК 533.951; 550.385

\title{
Ring Current Proton Dynamics Driven by Wave-Particle Interactions During a Nonstorm Period
}

\author{
Sergei V.Smolin* \\ Siberian Federal University \\ Krasnoyarsk, Russian Federation
}

Received 10.08.2020, received in revised form 10.09.2020, accepted 20.10.2020

\begin{abstract}
Modeling of pitch angle scattering of ring current protons at interaction with electromagnetic ion cyclotron waves during a nonstorm period was considered very seldom. Therefore it is used correlated observation of enhanced electromagnetic ion cyclotron (EMIC) waves and dynamic evolution of ring current proton flux collected by Cluster satellite near the location $L=4.5$ during March 26-27, 2003, a nonstorm period $(D s t>-10 \mathrm{nT})$. Energetic $(5-30 \mathrm{keV})$ proton fluxes are found to drop rapidly (e.g., a half hour) at lower pitch angles, corresponding to intensified EMIC wave activities. As mathematical model is used the non-stationary one-dimensional pitch angle diffusion equation which allows to compute numerically density of phase space or pitch angle distribution of the charged particles in the Earth's magnetosphere. The model depends on time $t$, a local pitch angle and several parameters (the mass of a particle, the energy, the McIlwain parameter, the magnetic local time or geomagnetic eastern longitude, the geomagnetic activity index, parameter of the charged particle pitch angle distribution taken for the 90 degrees pitch angle at $t=0$, the lifetime due to wave-particle interactions). This model allows numerically to estimate also for different geophysical conditions a lifetime due to wave-particle interactions. It is shown, that EMIC waves can yield decrements in proton flux within 30 minutes, consistent with the observational data. The good consent is received. Comparison of results on full model for the pitch angle range from 0 up to 180 degrees and on the model for the 90 degrees pitch angle is lead. For a perpendicular differential flux of the Earth's ring current protons very good consent with the maximal relative error approximately $3.23 \%$ is received.
\end{abstract}

Keywords: magnetosphere, ring current, pitch angle diffusion equation, data of the Cluster satellite, proton flux, wave-particle interactions.

Citation: S.V.Smolin, Ring Current Proton Dynamics Driven by Wave-Particle Interactions During a Nonstorm Period, J. Sib. Fed. Univ. Math. Phys., 2021, 14(1), 98-104.

DOI: 10.17516/1997-1397-2021-14-1-98-104.

\section{Introduction}

Electromagnetic ion cyclotron (EMIC) waves play an important role in precipitation losses of ring current ions and radiation belt electrons via wave-particle interactions during geomagnetic storms. Pitch angle diffusion induced by EMIC waves is considered as an efficient mechanism responsible for the ring current decay during active geomagnetic periods. Variation of radiation belt dynamics is considered as the contribution from wave-particle interactions and from drift resonance associated with enhanced ultra low frequency waves. For the review of the literature look, for example [1].

But simultaneous observation and corresponding modeling of pitch angle scattering of ring current protons by electromagnetic ion cyclotron waves during a nonstorm period have seldom been reported [1]. Therefore the purpose of work is modeling of pitch angle scattering of ring

*smolinsv@inbox.ru

(c) Siberian Federal University. All rights reserved 
current protons during a nonstorm period in the Earth's magnetosphere, using corresponding mathematical models.

\section{The mathematical model}

The following non-stationary differential equation is used [2,3] for phase space density, which describes the pitch angle diffusion and losses due to wave-particle interactions in the Earth's magnetosphere for a range of pitch angles from $0^{\circ}$ up to $180^{\circ}$ :

$$
\frac{\partial f}{\partial t}=\frac{1}{\sin \alpha} \frac{\partial}{\partial \alpha}\left(\sin \alpha D_{\alpha \alpha} \frac{\partial f}{\partial \alpha}-\frac{\sin ^{2} \alpha \cos \alpha}{2 L} \frac{d L}{d t} f\right)-\frac{f}{T_{w p}}+S_{\perp} \sin ^{2} \alpha f,
$$

where $f$ is the phase space density (or distribution function); $t$ is the time; $L$ is the McIlwain parameter; $\alpha$ is the local pitch angle; $D_{\alpha \alpha}$ is the coefficient of pitch angle diffusion; $d L / d t \approx\langle d L / d t\rangle$ is the bounce-averaged radial drift velocity of charged particles; $T_{w p}$ is the lifetime due to waveparticle interactions; $S_{\perp}$ is the perpendicular coefficient of the particle source function.

Equation (1) describes the pitch angle diffusion in the velocity space with losses due to waveparticle interactions. The loss function is conditioned by the fall of charged particles in the so-called "loss cone" as a result of wave-particle interactions. The particle source function can be related, for example, to charged particles that move from the tail of the magnetosphere toward the Earth when affected by magnetospheric convection.

The pitch angle diffusion coefficient is proposed to be determined from the formulas $[2,3]$

$$
D_{\alpha \alpha}=D_{\perp} \sin ^{2} \alpha=\frac{1}{\gamma_{\perp 0}\left(\gamma_{\perp 0}+2\right) T_{w p}} \sin ^{2} \alpha
$$

and $S_{\perp}$ to be determined as follows

$$
S_{\perp}=\frac{\left(\gamma_{\perp 0}+3\right)}{\left(\gamma_{\perp 0}+2\right) T_{w p}}
$$

In formulas (2) and (3) $\gamma_{\perp 0}$ is the well-known (when $f \sim \sin ^{\gamma} \alpha$ ) parameter of the charged particle pitch angle distribution (or the anisotropy index of pitch angle distribution) taken for the pitch angle of $90^{\circ}$ at the initial time.

The lifetime due to wave-particle interactions as a empirical function of the geomagnetic activity index $K p \leqslant 6$ we shall determine according to work [4]

$$
T_{w p}(K p)=T_{w p}(K p=0) \cdot(1-0.15 K p),
$$

where $T_{w p}$ for $K p=6$ is used for greater values of $K p$ as well.

Since $T_{w p}(K p=0)$ was not determined in [4], the following formula for calculation is offered

$$
T_{w p}(K p=0)=k T_{\min }=k \frac{2 T_{B}}{\alpha_{c}^{2}}=k \frac{2 R_{E} L^{4} \sqrt{4 L-3} \sqrt{m}}{\sqrt{2 E L}},
$$

where $k$ is a dimensionless parameter, $T_{\min }$ is the minimum lifetime of a charged particle, $T_{B}$ is a quarter of the bounce period, $\alpha_{c}$ is the pitch angle of the loss cone [5], $R_{E}$ is the Earth's average radius, $E$ is the particle energy, and $m$ is the particle mass.

Although the exact lifetime due to wave-particle interactions is unknown at such definition, formulas (4), (5) make it possible to estimate this time depending on the parameter $k$, the charged particle energy and mass, the McIlwain parameter, and the $K p$-index. This allows the influence of the lifetime due to wave-particle interactions on pitch angle diffusion in the Earth's magnetosphere to be simulated. 
The mathematical model of pitch angle diffusion of charged particles in the Earth's magnetosphere represented by (1)-(5) takes into account three physical mechanisms [6]. First, the wave-particle interactions are considered with $T_{w p}$ by (4) and (5). Second, the physical mechanism of injection and particle drift is taken into account through the radial drift velocity $d L / d t$ in equation (1). Third, since the electric field potential depends on the geomagnetic activity index $K p$ [2,3], we take into account the splitting effect of drift shells of the electric field on the pitch angle distribution of charged particles.

Equation (1) combined with (2)-(5) is a non-stationary, one-dimensional, second-order, partial differential equation. Its solution should be sought as a function of $\alpha$ and $t$. We use this solution to determine the evolution of the pitch angle distribution of the Earth's ring current protons during a nonstorm period.

\section{Results of calculations and comparison with experimental data}

The model is used for quantitative comparison of a modeling flux of protons with measurements of the Cluster satellite [1]. For this purpose it is considered correlated observation of enhanced electromagnetic ion cyclotron (EMIC) waves and dynamic evolution of ring current proton flux collected by Cluster satellite near the location $L=4.5$ during March 26-27, 2003, a nonstorm period (Dst $>-10 \mathrm{nT})$. Thus energetic $(5-30 \mathrm{keV})$ proton fluxes are found to drop rapidly (e.g., a half hour) at lower pitch angles, corresponding to intensified EMIC wave activities.

At the moment of time 00:00 RT $=23: 56$ UT on 26 March, 2003 (RT-"running", current time of modeling) $K p$-index of geomagnetic activity was equaled 2.66 or 3 and further within almost 3 hours remained to constant. As $K p$-index is a planetary three-hour index. Time of modeling for comparison with experimental data has been taken 30 minutes, i.e. 00:30 RT $=00: 26 \mathrm{UT}$ on 27 March, 2003.

The initial condition for the equation (1) in the moment of time 00:00 RT $=23: 56$ UT on 26 March, 2003 we shall take from work [1] where the pitch angle distribution measured on the Cluster satellite for energy $E=17.1 \mathrm{keV}$ is presented. This distribution (Fig. 1) is designated squares (nonstorm conditions). For the approached analytical description of initial experimental data it is used pitch angle distribution in the form of

$$
j(\alpha)=j_{\perp} \sin ^{\gamma} \alpha .
$$

The good consent turns out, when, for example, the perpendicular differential flux of protons is equal $j_{\perp} \approx 560360\left(\mathrm{~cm}^{2} \mathrm{~s} \mathrm{sr} \mathrm{keV}\right)^{-1}$, and a parameter of pitch angle distribution $\gamma=\gamma_{\perp 0}=0.5157$ (blue line on Fig. 1). In the same figure circles designate experimental data for energy $E=17.1$ $\mathrm{keV}$ in the moment of time 00:30 RT =00:26 UT on 27 March, 2003 (again nonstorm conditions).

In the further the following relationship between a differential flux of particles $j$ and phase space density $f$ (or function of distribution) $j=2 m E f$, where $m$ is the mass of the charged particle, in the given work of a proton will be used. Therefore we shall enter following boundary conditions: $j=0$ for $\alpha=0^{\circ}$ and for $\alpha=180^{\circ}$.

For pitch angle distributions the value of the parameter $k$ entering into definition of lifetime due to wave-particle interactions (4), (5), steals up the numerical decision of the equation of pitch angle diffusion (1)-(5) until the maximal modeling value of a differential flux will not coincide with the maximal experimental value of a differential flux at the pitch angle $90^{\circ}$. Using this criterion, numerically (trial and error method)the value $k=2.8 \cdot 10^{-6}$ has been certain.

On Fig. 1 corresponding comparison of experimental data (circles) and results of calculation in 30 minutes after the beginning of modeling (red line, $L=4.17, \mathrm{MLT}=22.58, E=17.1 \mathrm{keV}$, $k=2.8 \cdot 10^{-6}, 00: 30 \mathrm{RT}=00: 26 \mathrm{UT}$ on $\left.27 \mathrm{March}, 2003\right)$ is presented. The good consent is 


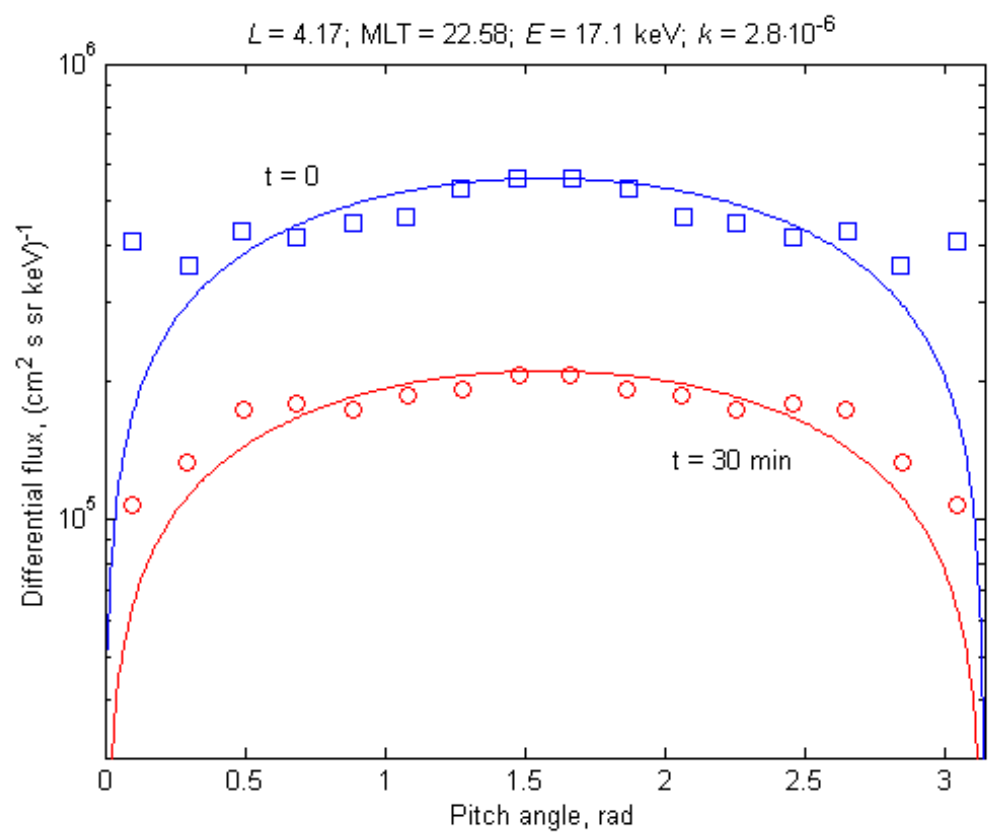

Fig. 1. The pitch angle distributions of protons measured of the Cluster satellite for $E=17.1 \mathrm{keV}$. Lines (squares and circles) specify a differential fluxes for 00:00 RT = 23:56 UT on 26 March, 2003 and for 00:30 RT = 00:26 UT on $27 \mathrm{March}, 2003$ (nonstorm conditions) respectively. Blue and red lines specify a modeling differential fluxes for 00:00 RT and 00:30 RT $(L=4.17$, MLT $=22.58$, $E=17.1 \mathrm{keV}, k=2.8 \cdot 10^{-6}$ ) respectively

received. It is visible, that for protons with energy $E=17.1 \mathrm{keV}, L=4.17$ on the nightside of the Earth's magnetosphere in nonstorm conditions a pitch angle distribution within 30 minutes remains similar to a pancake or normal.

Thus, on a concrete example of evolution of pitch angle distributions in nonstorm time quantitative opportunities of offered model of pitch angle diffusion in the Earth's magnetosphere are shown. By calculations it is proved and on Fig. 1 it is shown, that mathematical model (1)-(5) adequately describes pitch angle distributions. The model of pitch angle diffusion (1)-(5) allows to model and predict pitch angle distributions for the different charged particles (protons, electrons, positively charged ions and so on) depending on mass of the charged particle, its energy, the McIlwain parameter, value of magnetic local time MLT, initial perpendicular value of a parameter of pitch angle distribution of particles, the variable parameter $k$ determining the lifetime due to wave-particle interactions, and $K p$-index of geomagnetic activity. Thus in model such possible physical mechanisms of formation of pitch angle distributions as wave-particle interactions, injection and drift of particles, splitting of drift shells of the electric field are simultaneously considered.

Using [7], it is offered the ordinary differential equation for the description of a perpendicular differential flux of the charged particles $\left(\alpha=90^{\circ}\right)$ in the Earth's magnetosphere which depends on time and several parameters:

$$
\frac{d j_{\perp}}{d t}+\left(-\frac{1}{2 L} \frac{d L}{d t}+\frac{\gamma_{\perp}-\gamma_{\perp 0}}{\gamma_{\perp 0}\left(\gamma_{\perp 0}+2\right) T_{w p \perp}}\right) j_{\perp}=0,
$$

where $j_{\perp}$ is the perpendicular differential flux of the charged particles, $\gamma_{\perp 0}$ is the parameter of the charged particle pitch angle distribution (or the pitch angle distribution anisotropy index) 


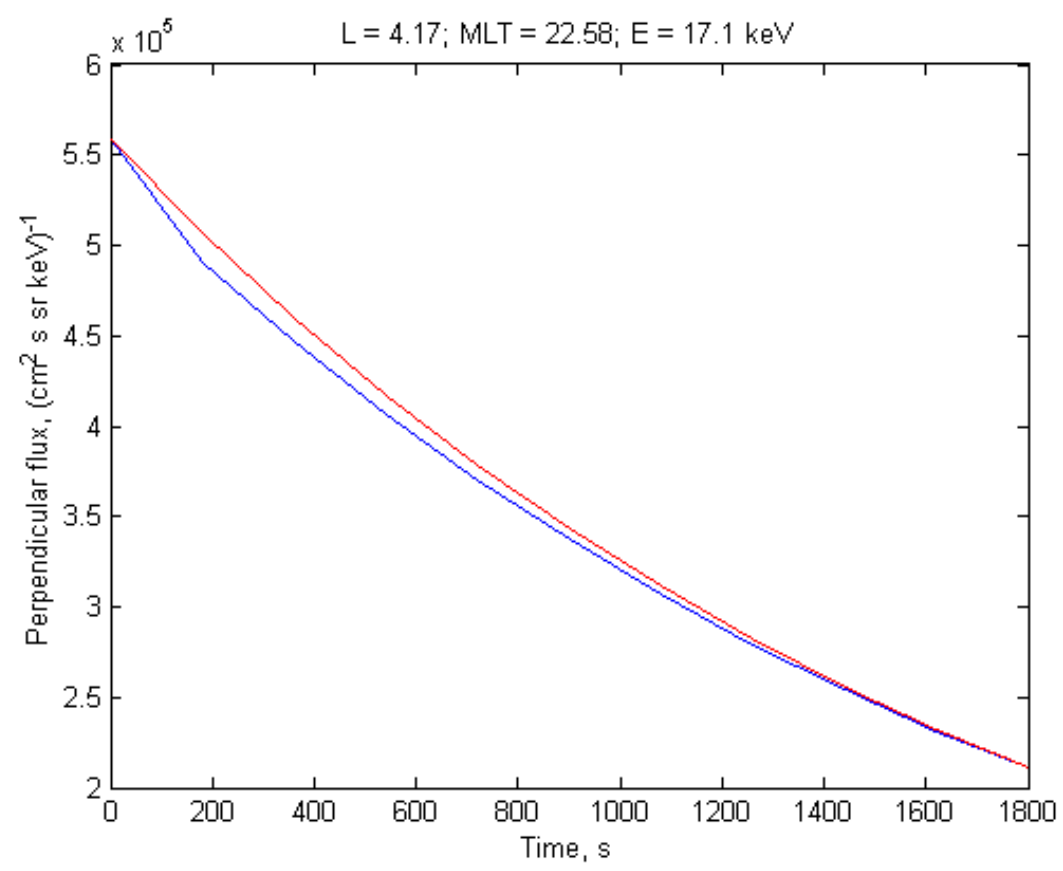

Fig. 2. Differential fluxes of protons for the $90^{\circ}$ pitch angle on full model (1)-(6) - the bottom (blue) line and on the model (7) or (8) - the top (red) line

taken for the $90^{\circ}$ pitch angle at $t=0, \gamma_{\perp}$ is the average parameter of the charged particle pitch angle distribution on an interval of time of calculation (it is supposed, that $\gamma_{\perp} \approx$ const).

Under the certain geophysical conditions and on a time interval approximately no more than three hours (when a geomagnetic activity index $K p=$ const) or on a greater time interval, when $K p \approx$ const, the equation (7) can be solved analytically.

Then the analytical solution of the equation (7) is

$$
j_{\perp}(t)=j_{\perp 0} \exp \left(-\left(\frac{\pi \phi_{2} L^{3} \cos \phi}{7948800}+\frac{\gamma_{\perp}-\gamma_{\perp 0}}{\gamma_{\perp 0}\left(\gamma_{\perp 0}+2\right) T_{w p \perp}}\right) t\right) .
$$

Here, $j_{\perp 0}$ is the perpendicular differential flux of the charged particles at $t=0, \phi_{2}$ in [8], and $\phi$ is the azimuthal angle (local time $\mathrm{LT}=0 \mathrm{~h}$ at midnight) or geomagnetic eastern longitude in the magnetic equator plane.

For calculation we shall take following data [1]: $j_{\perp 0}(t=0 \mathrm{~s})=5.6036 \cdot 10^{5}\left(\mathrm{~cm}^{2} \mathrm{~s} \mathrm{sr} \mathrm{keV}\right)^{-1}$, $j_{\perp}(t=1800 \mathrm{~s})=2.1165 \cdot 10^{5}\left(\mathrm{~cm}^{2} \mathrm{~s} \mathrm{sr} \mathrm{keV}\right)^{-1}, K p=2.66$ or $3-, L=4.17, \phi \equiv \mathrm{MLT}=22.58 \mathrm{~h}$, $\gamma_{\perp 0}=0.5157, \gamma_{\perp}=0.5801, E=17.1 \mathrm{keV}$. Then using (8) turn out $T_{w p \perp}=92.5356 \mathrm{~s}$ and dependence $j_{\perp}$ from $t$ on the interval $t=(0-1800) \mathrm{s}$ (Fig. 2).

Comparison of results on the model (7) or (8) and on full model (1)-(6) for the pitch angle range from 0 up to 180 degrees is lead. For a perpendicular differential flux of the Earth's ring current protons very good consent with the maximal relative error approximately $3.23 \%$ is received.

Thus, using two presented models, it is adequately shown, that during a nonstorm period electromagnetic ion cyclotron waves can yield decrements in proton flux within 30 minutes, consistent with the observational data and ring current proton dynamics is driven by waveparticle interactions. 


\section{Conclusion}

1. The presented mathematical model of pitch angle diffusion in the magnetosphere (1)-(6) allows to count numerically a phase space density or charged particle pitch angle distribution depending on mass of a particle, its energy, the McIlwain parameter, value of magnetic local time, initial perpendicular value of a parameter of charged particle pitch angle distribution, the variable parameter $k$ determining lifetime due to wave-particle interactions, and $K p$-index of geomagnetic activity.

2. In model such possible physical mechanisms of formation of pitch angle distributions as wave-particle interactions, injection and drift of particles, splitting of drift shells of the electric field are simultaneously considered.

3. The model allows to find at presence initial and final (intermediate) pitch angle distributions the corresponding value $k$ and by that unequivocally to determine, predict for concrete conditions following characteristics: a lifetime due to wave-particle interactions, coefficient of pitch angle diffusion, functions of losses and a source of particles.

4. The model is tested quantitatively by comparison of modeling fluxes of protons with measurements of the Cluster satellite in nonstorm time (23:56 UT on 26 March - 00:26 UT on 27 March, 2003). The good consent is received.

5. Comparison of results on full model for the pitch angle range from 0 up to 180 degrees (1)-(6) and on the model for the 90 degrees pitch angle (7)-(8) is lead. For a perpendicular differential flux of the Earth's ring current protons very good consent with the maximal relative error approximately $3.23 \%$ is received.

6. It is adequately shown, using two presented models, that during a nonstorm period electromagnetic ion cyclotron waves can yield decrements in proton flux within 30 minutes, consistent with the observational data and ring current proton dynamics is driven by waveparticle interactions.

\section{References}

[1] F.Xiao, C.Yang, Q.Zhou, Z.He, Y.He, X.Zhou, L.Tang, Nonstorm time scattering of ring current protons by electromagnetic ion cyclotron waves, J. Geophys. Res., 117(2012), A08204. DOI: $10.1029 / 2012 J A 017922$.

[2] S.V.Smolin, Modeling of pitch angle distribution on the dayside of the Earth's magnetosphere, Journal of Siberian Federal University. Mathematics \& Physics, 5(2012), no. 2, 269-275 (in Russian).

[3] S.V.Smolin, Modeling the pitch angle distribution on the nightside of the Earth's magnetosphere, Geomagnetism and Aeronomy, 55(2015), no. 2, 166-173.

DOI: $10.1134 /$ S0016793215020152.

[4] Y.S.Miyoshi, V.K.Jordanova, A.Morioka, M.F.Thomsen, G.D.Reeves, D.S.Evans, J.C.Green, Observations and modeling of energetic electron dynamics during the October 2001 storm, J. Geophys. Res., 111(2006), no. A11, 502-513.

[5] D.Summers, R.M.Thorne, Relativistic electron pitch-angle scattering by electromagnetic ion cyclotron waves during geomagnetic storms, J. Geophys. Res., 108(2003), no. A4, $1143-1154$. 
[6] D.G.Sibeck, R.W.McEntire, A.T.Y.Lui, R.E.Lopez, S.M.Krimigis, Magnetic field drift shell splitting: cause of unusual dayside particle pitch angle distributions during storms and substorms, J. Geophys. Res., 92(1987), no. A12, 13,485-13,497.

[7] S.V.Smolin, The analytical description of the Earth's ring current proton flux for the pitch angle of 90 degrees, Space, Time and Fundamental Interactions, 27(2019), no. 2, 70-74. DOI: $10.17238 /$ issn2226-8812.2019.2.70-74

[8] A.Nishida, Geomagnetic diagnosis of the magnetosphere, New York, Springer-Verlag, 1978.

\title{
Динамика протонов кольцевого тока, управляемая взаимодействиями волна-частица, во время магнитоспокойного периода
}

Сергей В. Смолин

Сибирский федеральный университет Красноярск, Российская Федерация

\begin{abstract}
Аннотация. Моделирование питч-углового рассеяния протонов кольцевого тока при взаимодействии с электромагнитными ионно-циклотронными (ЭМИЦ) волнами во время магнитоспокойного периода было рассмотрено очень редко. Поэтому используется коррелированное наблюдение усиленных электромагнитных ионно-циклотронных волн и динамической эволюции потока протонов кольцевого тока, собранное спутником Cluster около положения $L=4.5$ 26-27 марта 2003 г. в магнитоспокойный период (Dst $>-10$ нТл). Потоки энергичных (5-30 кэВ) протонов спадают быстро (например, за полчаса) для маленьких питч-углов, соответствуя активностям интенсивных ЭМИЦ-вХолн. Как математическая модель используется нестационарное одномерное уравнение питч-угловой диффузии, которое позволяет численно вычислять плотность фазового пространства или питч-угловое распределение заряженных частиц в магнитосфере Земли. Модель зависит от времени $t$, локального питч-угла и нескольких параметров (массы частицы, энергии, параметра МакИлвейна, магнитного местного времени или геомагнитной восточной долготы, индекса геомагнитной активности, показателя питч-углового распределения заряженных частиц, взятого для питч-угла 90 градусов при $t=0$, времени жизни вследствие взаимодействий волна-частица). Эта модель позволяет также численно оценивать для разных геофизических условий время жизни вследствие взаимодействий волна-частица. Показано, что ЭМИЦ-волны могут производить уменьшения в потоке протонов за 30 минут, согласованные с данными наблюдений. Получено хорошее согласие. Проведено сравнение результатов по полной модели для области питч-углов от 0 до 180 градусов и по модели для питч-угла 90 градусов. Получено для перпендикулярного дифференциального потока протонов кольцевого тока Земли очень хорошее согласие с максимальной относительной ошибкой приблизительно $3.23 \%$.
\end{abstract}

Ключевые слова: магнитосфера, кольцевой ток, уравнение питч-угловой диффузии, данные спутника Cluster, поток протонов, взаимодействия волна-частица. 